\title{
The Approach of Applying Augmented Reality Application with Infographic for Supporting Health Care
}

\author{
Waralak V. Siricharoen ${ }^{1}$ * \\ ${ }^{1}$ Faculty of Information Communication and Technology \\ Silpakorn University, Thailand
}

\section{Abstract}

There are more and more people can access the technology, digital divide has been reduced over the years. In this paper intend
to clarify and demonstrated how Thailand want to apply the trendy and advance technology to provide the better well-being and
healthcare to Thais. The example of using augment reality technology application in the hospital are mentioned in this paper
along with the real scenarios. The patients can use the smartphone to learn about the useful information of the innovation products
by using the augment reality application on the phone.

Keywords: Augmented Reality, Application, Thailand, Hospital, Health Care

Received on 01 March 2018, accepted on 02 March 2018, published on 18 June 2018

Copyright $\odot 2018$ Waralak V. Siricharoen, licensed to EAI. This is an open access article distributed under the terms of the Creative Commons Attribution licence (http://creativecommons.org/licenses/by/3.0/), which permits unlimited use, distribution and reproduction in any medium so long as the original work is properly cited.

doi: 10.4108/eai.18-6-2018.154823

\section{Introduction}

The widespread adoption of electronic health records has resulted in significant savings in health care costs as well as improved patient health and safety. In more and more healthcare facilities, patient files are being kept in digital records that can be accessed from anywhere in the facility [1]. Furthermore, infographics can be used to overcome language barriers. Communicating with patients who do not speak English as their first language has become increasingly common in Northern Ireland due to changing trends in migration [2]. The plethora of "Healthcare Infographics" illustrates the seemingly countless ways health information is communicated visually across virtually every disease state and medical topic, and for every audience type from the public to specialists. With data becoming increasingly central to all aspects of healthcare, visualization techniques and tools are now an equally important part of every function from analytics to communications, ultimately transforming healthcare globally. Using a picture and graphics to represent data and information is called an infographic. It is a way to display complex data that shows assessments or graphs. To align with the goal of the development of Thailand Digital 4.0 , with a new means to prepare for the rise of the elderly population in health services. These will help people take care of themselves. By encouraging older people to learn digital technology. Modern digital media is the application of Augmented Reality, which integrates the real world into the virtual world through various types of interfaces. For example, smartphones, cameras, tablets, mobile cameras, etc., combine with the computing and software processes to render

*Corresponding author.Email: lak_waralak@yahoo.com 
3D Animations, etc. apply on the symbol object or AR code These technologies will make the content more interesting. It can transform the complex health information into the easier version and presented as the easy way to communication with the people who may need.

\section{Augmented Reality with Health Care Approach}

Augmented Reality ( $\mathrm{AR}$ ) is computer-generated content overlaid on a real-world environment. AR seeks to enhance experience by using the digital methods to overlay information/content over the real world. The goal is to add to, not replace what happening. It can supplement the real-world situation around the user with addition visuals and text. AR can be presented in many ways, such as from kiosks to enhanced glasses, mobile device/app with the camera which now is the most common method [3]. AR supports media such as videos and 3D models, via camera view in your smartphone, tablet, PC or via wearable technology for instance, viewfinder or smart glasses. A strong example of AR in practice is concerning healthcare. From a routine checkup to some complex medical operations, augmented reality can offer massive benefits and skills to both patient and medical experts [4]. Physical Exams: Integration of augmented reality assisted systems with patient record management technologies is already highly desirable utility. Future of Surgery: Augmented Reality and Surgical Navigation Systems in Figure 1 Video-assisted techniques have already revolutionized the way many surgical interventions are carried out, but with technologies like augmented reality, diagnosis and treatment will become even more accurate in the future. Surgical Procedures: AR provide interfaces to operating room medical devices, graphical overlay-based guidance, recording $\&$ archiving of procedures, live feeds to remote users, and instant access to patient records. AR has transformed the training and education of medicines into a more interactive session where the students can map the theory in the books to the real- world applications. AR applications have assisted in understanding the concepts in a better way by overlaying the information on 3D Printed human skeleton and can even give you the $3 \mathrm{D}$ illustration of anything from the textbooks. The technology could also be used for making augmented reality brochures/infographics for

\footnotetext{
${ }^{2}$ https://tech.co/tag/arnatomy

${ }^{3}$ anatomy4d.daqri.com

${ }^{4}$ https://www.accuvein.com/home/

${ }^{5} \mathrm{http}: / /$ sciencenetlinks.com/tools/eyedecide-app/
}

doctors for educating them on new therapies and drugs. The models can be accessed anytime and anywhere by anyone just by scanning the custom trackers and models pop up immediately [5]. The traditional methods involve textbooks, charts, flash cards and bone boxes which tried and tested methods giving results till date. To study the Anatomy of Human Body, the research create AR application called "ARnatomy", has added one more layer to this study pattern making it more interactive, also another AR application called "Anatomy 4D"," the application provide the interactive 4D experience of human anatomy to teachers, medical professionals, and students of all levels. The application called "AccuVein", is a handheld scanner that projects over skin and shows nurses and doctors where veins and their valves and bifurcations are in patients' bodies. They are of great help while performing cosmetic surgeries. EyeDecide ${ }^{5}$ application, doctors can show a simulation of a patient's vision. Augmedix 6 provides a technology- enabled documentation, so physicians do not have to check their computers during patient visits [6]. Augmented interactive Reality $^{7}$ (AiR) smart glasses platform, which is designed to enhance productivity not only in healthcare but in a wide range of other industries as well. AiR Glasses enable users to view the related-information right in their field-of-view and interact with it using familiar gestures, voice commands, and motion tracking. Medsights Tech ${ }^{8}$ developed a software to test the feasibility of using AR to create accurate 3dimensional reconstructions of tumors. And Figure 2 production of AR to pharma and scientific healthcare communications industry for pharma marketing, patient education, disease awareness.

\footnotetext{
${ }^{6}$ https://www.augmedix.com

${ }^{7} \mathrm{http}: / /$ atheerair.com/

${ }^{8} \mathrm{http}: / /$ www.medsightstech.com/
} 


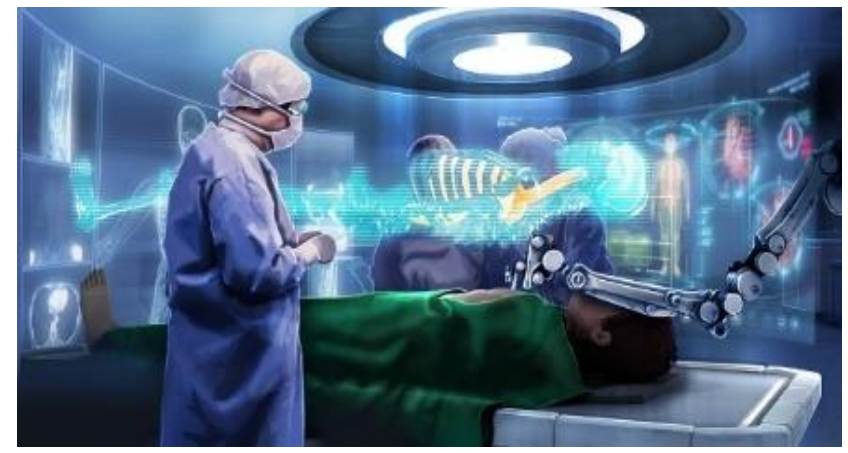

Figure 1. Future of Surgery: Augmented Reality and Surgical Navigation System. Source:

https:/c1.staticflickr.com/1/486/31501281374_81b237b6

$$
\text { 5b_b.jpg }
$$

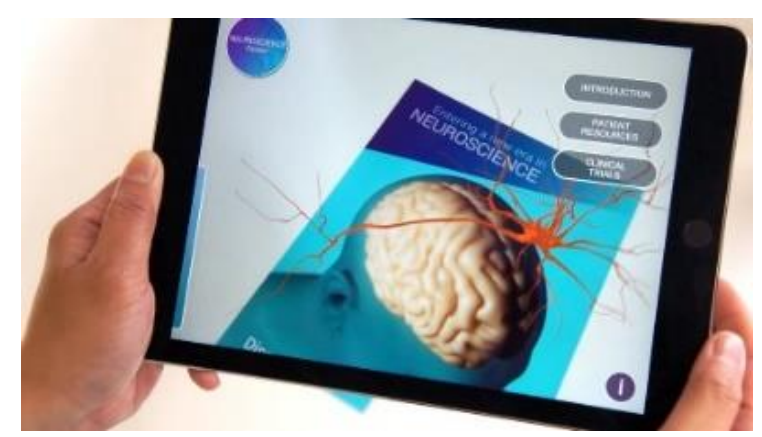

Figure 2. Augmented Reality (AR) Neuroscience Pipeline Teaser - Polygon Medical Animation Source

https:/i.vimeocdn.com/video/632884557_1280x720.jpg

\section{Infographic in Health Care Communication}

Publishers are taking a more visual approach to publishing whether that is creating more photo-based posts, integrating infographics or letting users to generate and share their own visual content but certain visually focused platforms have experienced enormous growth [7]. Infographic will help, as graphic visual representations of complex data are mean to present. In health care commination, infographics can be used for just about anything. They are great for primers on complex topics such as hospital quality data and reporting [8]. The way an Infographic is promoted is not the only thing to keep in mind; Subject, Design and Layout are keys. Infographics come up with all shapes and sizes, limited only by the imagination of the designer. The bottom line is that infographics distribute a common objective and principle, it is to communicate messages in an attractive, exciting and educational way [9]. The best interest is that we need to focus on the story, or the content [10]. In this case we need the audience to understand the health care information provided on the publications such as both motion and printed infographic. These infographics will deliver the complex health care message effectively. Therefore, infographic must be well- present and have enough useful information. Information visualization is the technique to describe the attention-grabbing fact of the data. The visualization designs are some words to let the data communicate. It has developed into a great way to tell stories [10]. These are some healthcare infographics as show in the google image search results in Figure 3 .

\section{Case study: applying the Augmented reality with infographic booklet with the smartphone application}

In this case study, ADDIE model has been developed to use as a guideline for development method, it based on the principles of a systematic approach or a conceptual approach consisting of 5 steps: 1) Analysis 2 Design 3) Development 4) Implementation and 5) Evaluation. The AR application was developed on the Android operating system. An application named "RamaInno" based on the AR on Android operating system created by the Ramathibodi Innovation Management Unit, Ramathibodi Hospital. Information of the innovation in the unit, previously, the information is shown in the form of digital media such as posters and animations or videos. Occasionally, the digital media is jerky or silent, slow display or error display, or may not display at all. Researchers are advised to use the Augment Reality application on the Android operating system (with the RamaInno application). The process and scope of work by using " media production theory" as shown in Figure 4, which need to be prepared for planning and management prior to production. There are 3 steps: 1) Pre-production Pre-production 2) Production 3) Postproduction Post-production and 4) Evaluation, which is the basis of $3 \mathrm{P}+1 \mathrm{E}$ 


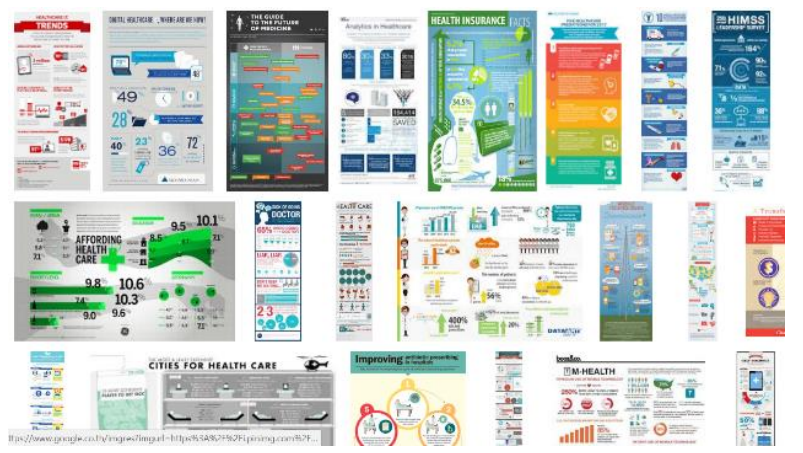

Figure 3. Infographics about Health Care available online

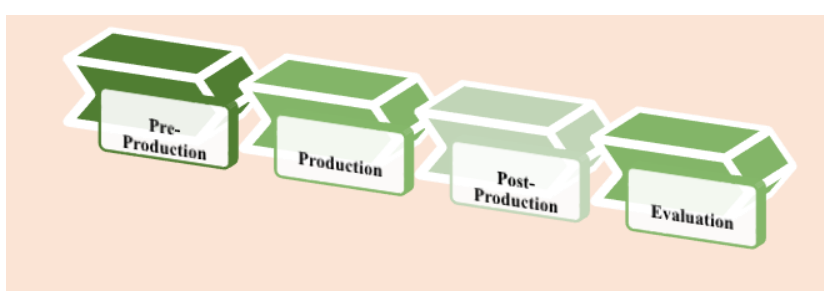

Figure 4. Media Production Theories 3P $+1 \mathrm{E}$

Table 1. The 3P+1E order and steps for AR application developing

\begin{tabular}{|l|l|}
\hline \multicolumn{1}{|c|}{ 3P+1E } \\
\hline Processes & \multicolumn{1}{|c|}{ Steps } \\
\hline Production & $\begin{array}{l}\text { The preparation process to determine all } \\
\text { production guidelines. The design process } \\
\text { is important. It is the direction of all work. } \\
\text { The details are. } \\
1 \text { Study and research relevant } \\
\text { information: } \\
\text { 1.1) Study and research related to the } \\
\text { practice of the elderly for mental health } \\
\text { and physical health with specialists. } \\
\text { Disease prevention and health promotion } \\
\text { Nursing Department Ramathibodi } \\
\text { Hospital } \\
1.2 \text { ) Analyze and study information } \\
\text { related to manuals, digital media, } \\
\text { Augmented Reality, Android SDK, Java } \\
\text { SDK }\end{array}$ \\
\hline
\end{tabular}

\begin{tabular}{|c|c|}
\hline \multicolumn{2}{|r|}{$3 P+1 E$} \\
\hline Processes & Steps \\
\hline & $\begin{array}{l}\text { 1.3) Learn Adobe Illustrator, Adobe } \\
\text { Photoshop, Adobe Flash, Unity 3D, Corel } \\
\text { VideoStudio. } \\
\text { 2) Define the content of information and } \\
\text { elements such as Idea, SCRIPT, color, } \\
\text { format and size of characters. } \\
\text { 2.1) Printed Media Guide } \\
\text { 2.2) AR Code } \\
\text { 2.3) Splash Screen and ICON on the } \\
\text { application. } \\
\text { 2.4) Digital media is text, images, } \\
\text { audio and video. } \\
\text { 2.5) Information on mental health } \\
\text { and physical health in } 7 \text { aspects: 1) Food 2) } \\
\text { Exercise } 3 \text { ) Sleeping } 4 \text { ) Excretion } 5 \text { ) } \\
\text { Emotional and Stress } 6 \text { ) Social } \\
\text { participation 7) Fall prevention } \\
\text { 2.5.1) Message } \\
\text { 2.5.2) illustration } \\
3 \text { ) Analyze and design the system } \\
\text { structure by defining Use Case Diagrams. } \\
\text { An additional AR on the Android } \\
\text { operating system (Heath application). }\end{array}$ \\
\hline $\begin{array}{l}2 . \\
\text { Production }\end{array}$ & $\begin{array}{l}\text { It is a step that will convey the design to } \\
\text { the media such as manuals, printed media, } \\
\text { digital media, etc. can present. In this } \\
\text { process, it consists of content presentation } \\
\text { media and use the program. } \\
\text { 1) Development of print media. "The } \\
\text { Elderly's Handbook for Mental Health and } \\
\text { Physical Health with AR". And illustrate } \\
\text { the practice of the elderly for mental } \\
\text { health and physical health in } 7 \text { aspects. } \\
\text { 2) develop AR code } \\
\text { 3) Develop Screen and ICON on the } \\
\text { application. } \\
\text { 4) Development of digital media is text, } \\
\text { image and video. } \\
\text { 5) Developing an AR Application on the } \\
\text { Android Operating System. }\end{array}$ \\
\hline $\begin{array}{l}\text { 3. Post- } \\
\text { Production }\end{array}$ & $\begin{array}{l}\text { It is a step to improve from the previous } \\
\text { design. It's like revising and fixing all the } \\
\text { errors correctly and completely. Before } \\
\text { publishing and publicizing. } \\
\text { 1) Test and modify the developed work. }\end{array}$ \\
\hline
\end{tabular}

EAI Endorsed Transactions on Context-aware Systems and Applications 032018 - 062018 | Volume 4 | Issue 14 | e5 


\begin{tabular}{|c|l|}
\hline \multicolumn{1}{|c|}{ 3P+1E } \\
\hline Processes & \multicolumn{1}{|c|}{ Steps } \\
\hline & $\begin{array}{l}\text { 2) Publish and publicize the "Practices } \\
\text { for Aging for Mental Health and Physical } \\
\text { Health with AR" and Android smartphones } \\
\text { with installed apps. Heath applications to } \\
\text { elderly people who come to Ramathibodi } \\
\text { Hospital and the elderly have tested with 5 } \\
\text { users. }\end{array}$ \\
\hline 4.Evaluation & $\begin{array}{l}\text { 1) The results of the application } \\
\text { performance testing of the AR on the } \\
\text { Android operating system ( Heath } \\
\text { application) } \\
\text { 2) Satisfaction evaluation results } \\
\text { 2.1) Printed Media Guide "A Guide } \\
\text { for the Elderly for Mental Health and } \\
\text { Physical Health with AR" } \\
\text { 2.2) Ancillary technical applications } \\
\text { on the Android operating system (Heath } \\
\text { application) }\end{array}$ \\
\hline
\end{tabular}

The instruction of using the AR application (Figure 4) are followings:

1) Install the AR application on the smartphone with android operating system

2) Use the smartphone to scan the AR code (Figure 5, 6,7 ) on the booklet, the smartphone should be place where the appropriate amount of light, which should not be too dark or too bright

3) Digital media information is the animation or video displayed on the AR Code. It will continue playing forward until the end, so that it will loop through the replay.

4) User may change to another AR code or stop scanning the AR code. If user come back to scan the AR code for the original video or animation. The video or animation will continue to play.

5) AR Code must always appear because it affects the display. If the AR code is lost or dropped from the receiving part or the device used to receive the image. It will render the impression incompletely.

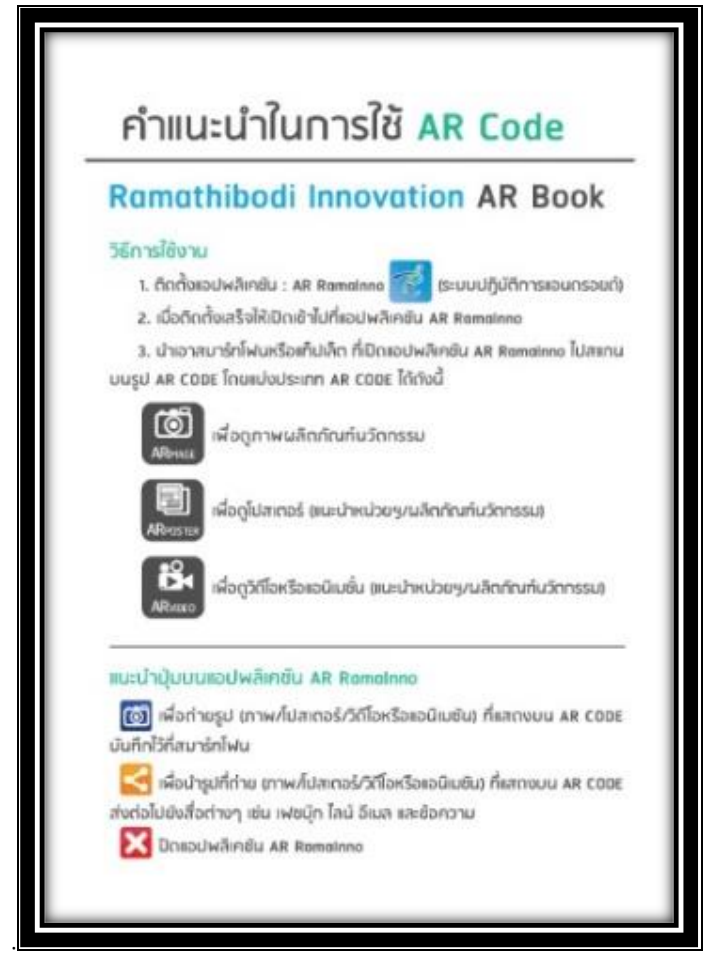

Figure 4. The instruction on the AR book with the smartphone AR application

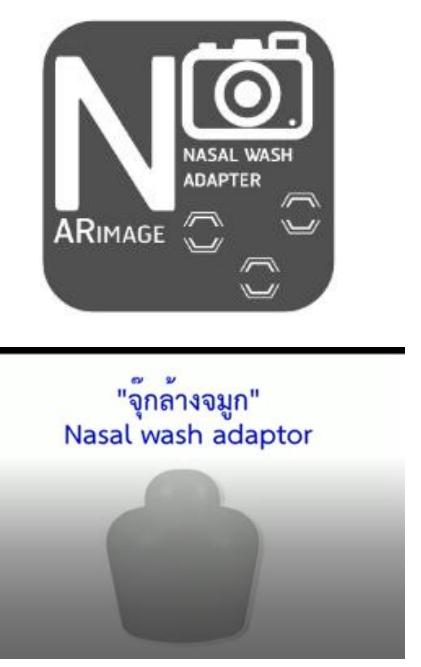

Figure 5. Example of the nasal wash AR code for image 

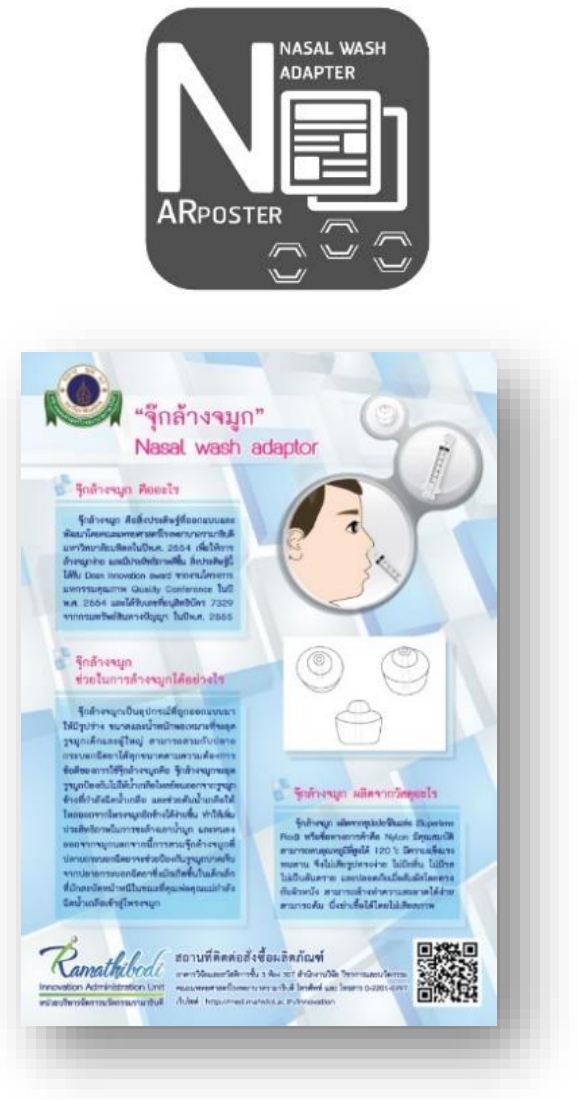

Figure 6. The nasal wash AR code for infographic poster

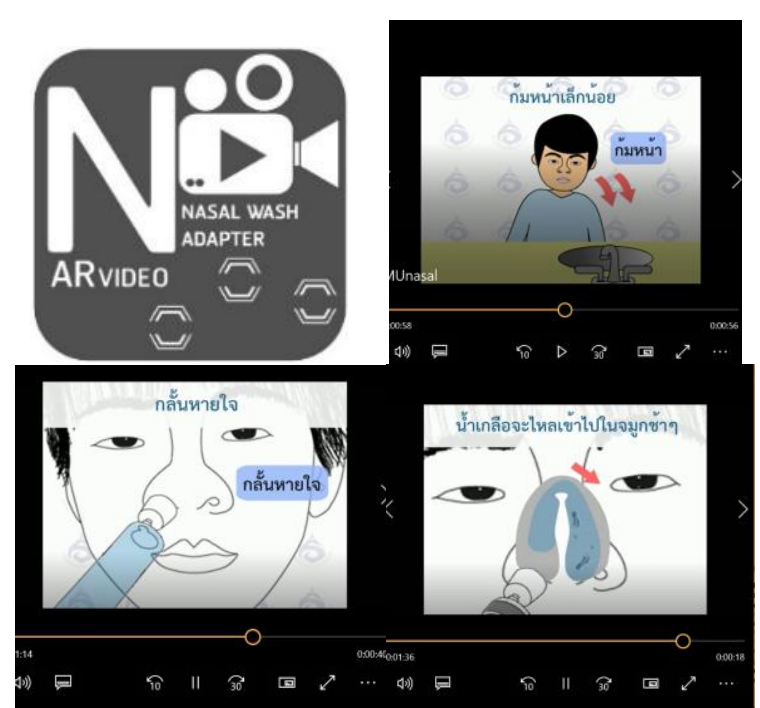

Figure 7. The nasal wash AR code for video
Results of data analysis on satisfaction assessment of users of AR applications on the android operating system, which use for presenting information through print media. These applications can be used with the smartphone. After that, the satisfaction questionnaires were delivered manually, The total number of questionnaires was 30 , total $100 \%$ of respondents.

1) The majority of the 30 respondents were 19 female which is $63.3 \%$ and males $36.7 \%$. Most of respondents were between 31-40 years of age, followed by those between 21-30 years old and 40 years old, respectively.

2) Satisfaction with using the AR application to provide information through the publication of the booklet. The overall satisfaction of the users was at the highest satisfaction level $(\mathrm{X}=4.43, \mathrm{SD}=0.60$ ).

3) Another suggestion is to separate the AR image for easy scanning. Pictures should be in $3 \mathrm{D}$, it will help motivating the user.

\section{The conclusion and discussion}

The author found that from the case study, the presentation of information in digital media through print infographic using the supplemental AR applications on the android operating system. The infographic and videos or animations which were presented from AR application, this can build the interest and create new excitement and experience for the users. The content related with the image in the infographic can float out of print media and display on smartphone screens in graphical, video, or animation. The users can easily access information anytime, anywhere. Also, they can be share the information online through social media quickly and instantly, such as Facebook, Twitter, and Instagram. It is more accessible and responsive to the needs of consumers in the digital age. The important thing is the user can experience augmented reality as the storytelling medias and tools to all the people who need better healthcare communication.

\section{Acknowledgments.}

I would like to express my special appreciation and thanks to Miss Sunisa Chusong, researcher from Ramathibodi Hospital for the useful information on showing the RamaInno AR Application as the research's case study. She did the work while she was attempting to pursue her Master degree at STOU. She provided the information about the RamaInno application and also presented the satisfaction result on using the AR application to the author which was demonstrated as the case study in this research. 


\section{References}

[1]Banova, B. 2013. The Impact of Technology on Healthcare, Available from: https://www.aimseducation.edu/blog/theimpact-of-technology-on-healthcare/

[2] Russell, R.(2012) Migration in Northern Ireland: an update. Belfast: Northern Ireland Assembly Research and Information Service; 2012. NIAR 10-12 Research Paper 31/12. Available from: http://www.niassembly.gov.uk/globalassets/documents/raise/ publications/2012/general/3112.pdf.

[3] Hutchinson, A. (2017) Virtual and Augmented Reality: What Brands Need to Know [Infographic]. Available from: http://www.socialmediatoday.com/marketing/virtual-andaugmented-reality-what-brands-need-know-infographic

[4] RealityTechnologies.com. (2016) Augmented Reality. Available from: http://www.realitytechnologies.com/augmented-reality

[5] Hassani, P. (2017) Applications of Augmented Reality in the Field of Medical Sciences - Part 1. Available from: https://blogs.systweak.com/2017/05/applications-ofaugmented-reality-in-the-field-of-medical-sciences/

[6] The Medical Futurist; Webicina Kft., (2017) The Top 9 Augmented Reality Companies in Healthcare. Available from: http://medicalfuturist.com/top-9-augmented-realitycompanies-healthcare/

[7] column five.com, (2015) EVERYTHING YOU NEED TO KNOW ABOUT VISUAL CONTENT. Available from: https://www.columnfivemedia.com/book

[8]Siricharoen W. V., Siricharoen, N. (2017) Infographic Utility in Accelerating Better Health Communication, Mobile Netw Appl DOI 10.1007/s11036-017-0900-3, Springer Science + Business Media, LLC 2017. Available from: https:/link.springer.com/article/10.1007/s11036-017-0900-3

[9] Siricharoen W. V. (2013) Infographics: An Approach of Innovative Communication Tool for E-Entrepreneurship Marketing,: International Journal of E-Entrepreneurship and Innovation (IJEEI) 4(2) Pages: 18-36.

[10] Siricharoen, W. V. , Vinh, P. C. (2017) Question matrix method according to divided dimensions of infographics evaluation. Pers Ubiquit Comput. (2017) 21:219-233. 